\title{
There is no archaeology but European archaeology ...
} \section{Thomas Meier}

To start with, I would like to emphasize that I very much agree with most points of Kristian Kristiansen's analysis of the European state of archaeology. In my view he is totally right in observing a turn from the global perspective to a national and local focus, expressed not least by narrowing language capabilities and restricted citation networks, both convincingly described in his paper. Furthermore he is right, I think, that archaeology has lost importance in the academic field due to its general avoidance of the grand questions, while at the same time the reviving myths of origin and heritage have prompted an unseen public interest in archaeology on the local level.

What I want to focus on in this comment is Kristiansen's model of prevailing archaeological theories swinging back and forth on the timeline between 'rationalist' and 'romanticist' approaches (figure 2) - which in my eyes widely correspond to the world views of science and the humanities. I think this model, as applied to archaeology, is convincing until the 1950s, but from then on Kristiansen concentrates on the Anglo-American development of archaeological theory only, which was widely adopted in northern Europe as well. In other parts of Europe, however, things were different. In the former Eastern Bloc, due to a materialist paradigm, scientific (processualist) concepts had some chance of being employed; postprocessual theory, however, was not in accordance with the Marxist world view. From the developments in the post-Soviet period it becomes apparent that Marxism was not (merely) imposed politically, but became deeply rooted in society, since even after 1989 the materialist-scientific paradigm prevailed (Suhr 2005; Smyntyna 2006). Other parts of Europe, like the German-speaking countries, for the most part did not adopt any ideas of (post)processual archaeology at all but became set on rejecting any theoretical reflection - scarce exceptions like Heiko Steuer and Manfred Eggert may pardon this very rough sketch. In this part of Europe it is only during the last few years that bits and pieces of scientific approaches which have been significant in the New Archaeology are - often unconsciously - adopted. Postprocessual approaches with their emphasis on contextualization, hermeneutics and constructivism - which in principle owe a very great deal to the German philosophical tradition - are still ignored or strictly rejected by a very broad majority (Bloemers 2000; Gramsch 2006, esp. 14 ff., who is slightly more optimistic on the recent past). 
While Kristiansen's sketch of developments in late 20th-century archaeological theory and practice across Europe may thus need some regional differentiation and take into account that since the $1950 \mathrm{~s}$ archaeological theory has split into a colourful bunch of coexisting branches, his observations on the pan-European narrowing of the archaeological mind towards a national and local focus indeed hold true. Thus his model is tackled, genetically equating the 'romantic' approach with national frames and local questions while a 'rationalist' approach would correspond to international networks and a global research interest. While we may observe a growing focus on the local and national across Europe, 'romantic' theoretical approaches are only practised in some parts and in some academic communities whereas others are working in a 'rational' framework. If the whole range from 'rational' to 'romantic' theory is indeed actually practised in Europe it cannot be the postprocessual approach alone, which is responsible for the pan-European concentration on the national and local. Moreover, former approaches like culture history and diffusionism, which Kristiansen summarizes as part of the 'romantic' approach, also provided too grand narratives on a global scale. Furthermore, ideas central to the humanities' approach to history like the concept of 'mentalities' (e.g. Bloch 1949; Febvre 1953) or Foucault's theory of 'discourse' (e.g. Foucault 1972) need not necessarily be pursued by quantifying, scientific methods, but provide 'romantic' approaches which work as well on a local level as on a supraregional or even a global one, or work better. So the absence of the grand narrative is neither restricted to archaeology nor has it been caused by the revival of 'romantic' theories, but it is embedded in the death of the metanarratives at the dawn of postmodernity (Lyotard 1982). Without doubt the humanities are much more susceptible to postmodern thinking than science is, but basically the scientific world view and its narratives are qualified and questioned in a postmodern world as well - even though some exponents of science and some parts of the public still ignore this dramatic change of the world around them.

Today, from a postmodern or humanities point of view, the natural-science paradigm is just one way of perceiving the world, not more or less true than any other ideology. Therefore I doubt that a swing back of archaeology towards a more scientific approach would better the explanatory potential of our subject - though it might improve its financial and institutional position in the short term, while the scientific world view prevails in the popular mind. Fierce battles between the scientific and humanities world views, however, have been fought for decades now without much benefit for academia or society as a whole and it does not seem very promising to continue these fruitless oppositions. Applying the Braudelian model of times (Braudel 1958), the swinging of the pendulum between 'rationalist' (scientific) and 'romantic' (humanities) theories, which Kristiansen describes, might be considered oscillations in the middle range. The short range would go to special theories like discourse theory, evolutionism, diffusionism and all those turns with a half-life period of less than a decade. But what about the long range?

If we try to observe ourselves from a distance, we become aware that archaeology is a very specific way of telling narratives about the past, 
narratives which help to create an identity - whether it be European, national or local - and an awareness of the world we are living in. It requires a specific methodology and it obeys specific rules of plausibility (Thomas 2004). Archaeology in itself is very much a cultural product: it comes from a very European tradition of thinking and reasoning, rooted thousands of years in the past. It is only the history of thought in this specific part of the world - starting at the latest in classical Athens - from which ideas like, for example, a continuity of time and space, the dualism of right and wrong and a very 'physical' concept of cause and effect have developed, which are basic to archaeology as to any other academic discipline. If we agree to call this tradition of thinking 'European' - regardless of the physical borders of Europe as a geographical construct - then strictly speaking all archaeology is a European archaeology in the cultural sense. If we accept archaeology to be a specific mode of thinking about the past, it is possible to tell archaeological narratives about non-European cultures, but there is no archaeology of nonEuropeans. Doubtless, colleagues from a non-European cultural background have learned archaeology and adapted it to their own (and other) cultures, but in these instances they act as cultural Europeans. Sure, archaeological concepts have been adopted, transformed and integrated by non-European cultures, but I do not find any intellectual benefit in enlarging the label 'archaeology' to these new configurations as well. Rather, as cultural products in their own right, it makes much more sense to allow them an academic label of their own.

Perceived from an assumed, though abstract, non-European perspective the different archaeologies of Europe have much more in common than it may seem from the intra-European perspective. Both the sciences and the humanities are deeply rooted in a common way of thinking and reasoning, in a common structure of argumentation and plausibility. Thus, in a society branded by an awareness of globalization, I am not sure whether it might be productive for archaeology to swing back to a more scientific approach once more and to continue oscillating between science and the humanities, between 'rational' and 'romantic' theories, both of which come with wellknown pitfalls. However, as archaeology is one of few disciplines very much at the border between the two academic faculties, archaeology receives a special potential (and responsibility) to develop new approaches combining and overcoming elements of both, often opposing, theoretical camps. In this attempt it may be worth realizing and considering the common intellectual basis of science and the humanities in a specific rationality (Mittelstraß 1999), becoming aware of the peculiarities of a European world view and of peculiarly European ways of telling narratives about the past. 